\title{
Büyükşehir Belediyelerinin Sportif ve Rekreatif Hizmetlerinin Niteliklerinin İncelenmesi
}

\author{
DOI: 10.26466/opus.806302
}

\author{
H. Erdem Mumcu* - Bahadır Aligül** - Ömür F. Karakullukçu*** \\ Yakup Paktaş ${ }^{* * * *}$ \\ * Dr., Tokat Gazi Osman Paşa Üniversitesi \\ E-Posta: erdemumcu@gmail.com \\ ORCID: $\underline{0000-0003-4325-5575}$ \\ **Uzman, Gençlik ve Spor Bakanlığı \\ E-Posta: bahadiraligull@gmail.com \\ ORCID: $0000-0003-2679-338 \mathrm{X}$ \\ *** Dr., Ankara Hacı Bayram Veli Üniversitesi \\ E-Posta: omurkarakullukcu@gmail.com \\ ORCID: $\quad$ 0000-0003-3343-5740 \\ **** Dr., Tokat Gazi Osman Paşa Üniversitesi \\ E-Posta: yakuppaktas55@gmail.com \\ ORCID: $\quad \underline{0000-0002-4857-3233}$

\section{Öz}

Bu çalşmanın amacl, Türkiye'de büyükşehir belediye hizmetlerinin içerisinde sporun yerinin ve kapsamının belirlenmesidir. Yerelde bu büyüklükte hizmet üreten bir kurumun spor yönetimi konusundaki eksikliklerinin belirlenmesi ve bu eksikliklerin giderilmesine yönelik önerilerde bulunmaktır. Yerel yönetimlerde eksik olduğu düşünülen spor hizmetlerinin standart bir hizmet politikası oluşturularak uygulamaya geçirilmesine ışık tutmaktır. Büyükşehir belediyelerinin verdikleri sportifhizmetler web sitelerinden, mail ve dilekçe yolu ile gerekli veriler elde edilmiştir. Elde edilen bulgular doküman analizi yöntemine uygun olarak toplanmıştır. Bulgular karşılaştırma yöntemi ile yorumlanmıştır. Bulgulardan elde edilen sonuca göre yerel yönetim birimlerinin spor hizmetlerinin web sayfalarından çok fazla yaygınlaştırılmadığı görülmüşsür. Ayrıca büyükşehir belediyelerinin pek çoğunda sportif hizmetlerine ait veriye ulaşılamamışıtı. Spor hizmetleri veren birimlerin de görev yapan birim sorumlularmmn sadece beşinin spor eğitimi aldığ görülmüştür. Spor hizmetlerinin on iki büyükşehir belediyesinde farklı daire başkanlikları altında faaliyet gösterdiği görülmü̈ştür. Spor tesis ve açık alanlarm çoğunda yetersiz olduğu görülmüştür. Sporda istihdam yaratma konusunda da eksikliklerin olduğu ve yeterli sayıda eğitmen istihdam edilmediği görülmektedir. Sporcu sayılarmmn ve faaliyet gösterilen spor dallarının kapasitelerinin düşük olduğu görülmüştür. Büyükşshir belediyelerinin spor/rekreasyon alanlarında şehirlerin niteliklerine ve halkın daha iyi hizmet almasına yardımcı olacak şekilde kurumsal internet sayfaların geliştirmeleri sonucuna ulaşılmıştır.

Anahtar Kelimeler: Spor Yönetimi, Büyükşehir Belediyeleri, Rekreatif Alanlar. 


\title{
Examination Of The Qualities Of Sports And Recreational Services Of Metropolitan Municipalities
}

\begin{abstract}
The aim of this study is to determine the place and scope of sports in metropolitan municipality services in Turkey. It is to identify the shortcomings of an institution that produces services of this size in the local area in terms of sports management and to make recommendations to address these deficiencies, to shed light on the implementation of sports services that are considered to be missing in local authorities by creating a standard service policy. In this study, the services provided by thirty metropolitan municipalities were obtained from the websites of the municipalities, by mail and petition. The findings were collected in accordance with the document analysis method. The results were interpreted by comparison method. According to the findings, local government departments have not been able to extend sports services too much from their web pages. In addition, data on sports services could not be reached in most of the metropolitan municipalities. It was observed that only five of the unit managers working in the units providing sports services received sports training. It has been observed that sports services operate under different departments in twelve metropolitan municipalities. It has been observed that most of the sports facilities and open spaces are insufficient. It is observed that there are also deficiencies in creating employment in sports and not hiring enough trainers. It has been observed that the number of athletes and the capacities of the sports branches in which they are active are low. It has been concluded that metropolitan municipalities also develop their web and online systems in sports / recreation areas in a way that will help the qualifications of the cities and provide better service to the public.
\end{abstract}

Keywords: Sports Management, Metropolitan Municipals, Recreational Area. 


\section{Giriş}

Günümüzde küreselleşen dünya üzerinde yeniden yapılanmalar, teknolojik değişimler, küresel ekonomi, yeni çalışma yöntemleriyle birlikte de spor dünya da önemli bir hizmet alanı haline gelmiştir (Bahadır, 2019). Fakat ülkemizde diğer pek çok alanda olduğu gibi spor hizmetleri de merkeziyetçi yönetim anlayışla yürütülmektedir. Bununla birlikte spor hizmetlerinin belediyeler eliyle halka ulaşması coğrafi, kültürel ve sosyo-ekonomik farklılıklara ve halktan gelecek demokratik yansımaya göre, hizmetlerin çeşitlendirilerek sporun faydalarının çok daha belirgin yaşanmasına imkân sağlamaktadır (Doğu, Kesim ve Sivrikaya, 2002). Spor, toplumları ve bireyleri bir araya getiren sosyal bir faaliyet olarak her geçen gün daha fazla önem kazanmaktadır (Özlü ve diğ., 2020). Sportif faaliyetler, bireylerin iş ya da çalışma zamanlarından arta kalan boş zamanlarında gönüllü olarak yer aldıkları faaliyetlerdir (Karakullukçu ve Karaküçük, 2017). Bu faaliyetler arasında performans sporu, fiziksel aktivite ve oyunun yanı sira farklı aktivitelerde yer almaktadır (Tütüncü ve diğer, 2011). Sporla ilgili yapılacak her türlü faaliyet bireylerde spor kültürü oluşmasına katkı sağlamaktadır (Havuç ve diğg., 2020). Bu kültürün oluşturulması için özellikle kent kültürü içerisinde yaşayan bireylerin hizmet alacakları alanların inşası gerekmektedir. Spor hizmetlerinin, belde sakinleri için bir belediyenin yapabileceği en önemli hizmetlerden biridir (Zengin ve Öztaş, 2008). Sporun topluma yaygınlaştırılması, yönetim, personel ve tesisler, malzeme, araç-gereç ve kitle iletişim araçlarının işleyişine, faaliyetlerin yeterliliğine, dengeli dağılımına, tüm sorumlulukların yerine getirilmesine bağlıdır (Çetin, 1986). Yerel politikalar toplumsal istek ve ihtiyaçların ortaya çıkmasıyla bu istek ve ihtiyaçlara cevap verecek şekilde siyasal yapının hukuk ve kurumsal geleneklere uygun bir şekilde harekete geçmesi olarak tanımlanmaktadır (Çevik ve Demirci, 2012). Kamu politikalarının alt araştırma alanını ise yerel seviyede kente dair mahalli ortak talepler çerçevesinde politikalar olduğu görülmektedir. Spor yönetimi de kamu politikaları içerisinde önemli bir yer tutmaktadır. Bu politikaların ana dayanağı devletin spora dair yaklaşımı 1982 Anayasası'nın 59. Maddesinde görülmektedir; “Devlet, her yaştaki Türk vatandaşlarının fiziksel ve psikolojik sağlığını geliştirecek önlemleri alır, sporun kitlelere yayılmasını teşvik eder. Devlet 
başarılı sporcuyu korur. Bununla birlikte merkezi ve yerel yönetimlerin sporun kitlelere yaygınlaştırılması için her yaşta insanın spor yapabileceği rekreatif alanlar oluşturmak, spor tesisleri yapmak ve sporcu yetiştirmek gibi spor politikaları geliştirmeye yönelik çalışmalar yaptığı bilinmektedir (Arslan ve diğ., 2011). Yerel yönetim birimlerinin verecekleri hizmetlerinin 2005 senesine değin yürürlükte kalan 1930 tarihli 1580 sayılı Belediye Kanunu'nun 15. maddesinde belediyelerin yetki ve vazifeleri belirtilmiştir. 82 vazifeden biri de "oyun ve spor yerleri yapmaktır" kanunun 33. maddesinde ifade edilmiştir. Tekrar aynı kanunun 54. maddesinde "Gençler için mahallinin ihtiyacıyla mütenasip stadyumlar tesis etmek ve işletmek" de belediyelerin vazifeleri arasında gösterilmiştir. Cumhuriyet' in ilk yıllarında ülkenin koşulları göz önüne alındığında bu kanunun son derece iyi hazırlandığ görülmektedir (Atasoy, 1992). Fakat 1580 sayılı kanunda sporla alakalı vazifeler diğer vazifelerle karşılaştırıldığında son derece yetersiz olduğu görülmektedir. Tarihsel süreçte belediye-spor ilişkisini inceleyen Fişek (2003)'e göre kanundaki yetersizliğe ek olarak, belediyeler için sporla alakalı vazifelerin öncelikli bir vazife olmadığı mali yetersizlik durumunda sportif faaliyetlere kaynak ayırmalarının mümkün olmadığını işaret etmektedir. Yapılan çalışmalar doğrultusunda yeniden güncellenen 5393 Sayılı yasa 2005 yılında yayınlanmıştır. Bu yasanın yayınlanmasıyla 1580 sayılı yasa yürürlükten kalkmıştır. 5393 sayılı yasanın 14. Maddesinde belediyelerin yetki ve vazifeleri (a) ve (b) bentlerinde belirtilmiştir. (a) bendi asli (b) bendi ise tali vazifeler olarak kabul edilmektedir. Ayrıca 5216 sayılı büyükşehir belediyelerinin görevlerinin başında; yetişkinler ve ileri yaş grupları, zihinsel ve fiziksel engelliler, kadınlar, gençler ve çocuklara yönelik her alanda sosyal ve kültürel faaliyetleri gerçekleştirmek, geliştirmek ve bu amaçla sosyal tesisler kurmak veya işlettirmek yer almaktadır (5216 Sayılı Büyükşehir Belediyesi Kanunu, 2004). Buna ek olarak büyükşehir belediye kanunun 7.maddesine göre "Büyükşehir' in bütünlüğüne hizmet eden sosyal donatılar, bölge parkları, hayvanat bahçeleri, hayvan barınakları, kütüphane, müze, spor, dinlence, eğlence ve benzeri yerleri yapmak, yaptırmak, işletmek veya işlettirmek; gerektiğinde amatör spor kulüplerine nakdî yardım yapmak, malzeme vermek ve gerekli desteği sağlamak, amatör takımlar arasında spor müsabakaları düzenlemek, yurt içi ve yurt 
dışı müsabakalarda üstün başarı gösteren veya derece alan sporculara, teknik yönetici, antrenör ve öğrencilere belediye meclis kararıla ödül vermek" şeklinde tanımlanmıştır (5261 Sayılı Büyükşehir Belediyesi Kanunu, 2004). İlgili kanunda büyükşehir belediye meclisinin spor ihtisas komisyonu kurulmasının yasal bir zorunluluk olduğu belirtilmiştir.

Yerel yönetimler ile alakalı olarak, hükümet politikalarıyla ortaklaşa hareket etmesi ve belediyelerin sorumlu oldukları bölgelerde gerekli çalışmaları ivedilikle yapması gerekliliğinden bahsedilmektedir (Altuntaş ve diğ., 2020). Görüldüğü üzere büyükşehir belediyelerinin yerelde spor konusunda pek çok alanda işlevsel görevler ve sorumlulukları bulunmaktadır. Bu doğrultuda araştırmanın ülkemizdeki büyükşehir belediyelerinin spor hizmetlerinin kalitesi ve niteliklerinin belirlenmesi açısından önemlidir.

\section{Yöntem}

Araştırmanın amacı büyükşehir belediyelerinin sportif ve rekreatif faaliyetlerinin niteliklerinin incelenmesidir. Araştırma Türkiye'de mevcut faaliyet gösteren otuz büyükşehir belediyesinde yapılmıştır. Araştırma literatür taraması, bilimsel ve doküman analizi kullanılarak yapılmıştır. Yapılan analiz sonucunda büyükşehir belediyelerinin salon ve tesis sayısı, faaliyet gösterilen spor branşları, sporcu sayıları, açık rekreatif alanları, sporu yöneten birim, sporu yöneten birimin yöneticilerinin eğitim durumu ve niteliği, antrenör sayısı ve üye sayıları incelenmiştir. Yapılan inceleme sonucunda büyükşehir belediyelerinin sportif ve rekreatif yönden yukarıda belirtilen değişkenler üzerinden karşılaştırması yapılmıştır. Elde edilen bilgiler bilgi edinme kanuna (4982 Bilgi Edinme Hakkı Kanunu 4. Maddesine göre herkes bilgi edinme hakkına sahiptir) dayalı olarak dilekçe ve mail yolu ile toplanmıştır. Ayrıca büyükşehir belediyelerinin resmî sitesinde yer alan kurumsal online web sayfalarından; sporcu sayıları, spor merkezleri, projeler, hizmetler, belediyelerin ilgili daire başkanlıklarında yer alan bilgilerden ulaşılmıştır. Buna ek olarak büyükşehir belediyeleri stratejik planlarının amaç ve hedeflerinin spor hizmetleri açısından incelemek üzere verilerin elde edildiği doküman türü olarak otuz büyükşehir belediyesinin 2010-2020 yılları arasını kapsayan stratejik planları büyükşehir belediyeleri online web sayfaları üzerinden, 
resmi dilekçe ve mail yoluyla elde edilmiştir. Elde edilen bulgular yorumlanarak tartışılmıştır.

\section{Bulgular}

Tablo 1. Büyükşehir Belediyelerinin Nüfuslarn

\begin{tabular}{|c|c|c|c|c|c|c|}
\hline Sira & Yil & İl & Toplam Nüfus & $\begin{array}{l}\text { Salon ve Tesis } \\
\text { Sayıs }\end{array}$ & Park ve Bahçeler & Üye Sayısı \\
\hline 1 & 2020 & Adana & 2.237 .940 & 52 & 86 & 70.000 \\
\hline 2 & 2020 & Ankara & 5.639 .067 & 38 & 38 & 250.000 \\
\hline 3 & 2020 & Antalya & 2.511 .700 & 3 & 65 & 80.000 \\
\hline 4 & 2020 & Aydın & 1.110 .972 & 1 & 1 & 30.000 \\
\hline 5 & 2020 & Balıkesir & 1.228 .620 & 1 & 7 & 30.000 \\
\hline 6 & 2020 & Bursa & 3.056 .120 & 15 & 9 & 130.000 \\
\hline 7 & 2020 & Denizli & 1.037 .208 & 29 & - & 28.000 \\
\hline 8 & 2020 & Diyarbakır & 1.756 .353 & 9 & - & 45.000 \\
\hline 9 & 2020 & Erzurum & 762,062 & 12 & - & 17.000 \\
\hline 10 & 2020 & Eskişehir & 887,475 & - & - & - \\
\hline 11 & 2020 & Gaziantep & 2.069 .364 & 55 & - & - \\
\hline 12 & 2020 & Hatay & 1.628 .894 & 7 & 2 & 12.000 \\
\hline 13 & 2020 & İstanbul & 15.519 .267 & 83 & 290 & 700.000 \\
\hline 14 & 2020 & İzmir & 4.367 .251 & 11 & 13 & 200.000 \\
\hline 15 & 2020 & Kahramanmaraş & 1.154 .102 & 16 & - & 23.000 \\
\hline 16 & 2020 & Kayseri & 1.407 .409 & 15 & - & - \\
\hline 17 & 2020 & Kocaeli & 1.953 .035 & 44 & 129 & 48.000 \\
\hline 18 & 2020 & Konya & 2.232 .374 & - & - & - \\
\hline 19 & 2020 & Malatya & 800,165 & 18 & - & - \\
\hline 20 & 2020 & Manisa & 1.440 .611 & 4 & - & - \\
\hline 21 & 2020 & Mardin & 838,778 & - & - & - \\
\hline 22 & 2020 & Mersin & 1.840 .425 & 14 & 112 & 55.000 \\
\hline 23 & 2020 & Muğla & 983,142 & 9 & 7 & 26.000 \\
\hline 24 & 2020 & Ordu & 754,198 & 7 & 7 & 20.000 \\
\hline 25 & 2020 & Sakarya & 1.029 .650 & 9 & 10 & 40.000 \\
\hline 26 & 2020 & Samsun & 1.348 .542 & 4 & 6 & 48.000 \\
\hline 27 & 2020 & Şanlıurfa & 2.073 .614 & 7 & 66 & 45.000 \\
\hline 28 & 2020 & Tekirdağ & 1.055 .412 & - & - & - \\
\hline 29 & 2020 & Trabzon & 808,974 & 10 & 112 & 29.000 \\
\hline 30 & 2020 & Van & 1.136 .757 & 5 & 39 & 32.000 \\
\hline
\end{tabular}

Tablo 1'de İstanbul'un 15.519.267 Ankara'nın 5.639.067 İzmir' in 4.367.251 olduğu görülmektedir. Nüfusun en yoğun olduğu iller Marmara bölgesindedir. 26 büyükşehir belediyesinde salon ve tesis sayısı verilmiş, 4 Büyükşehir belediyesinde verilmemiştir. 17 büyükşehir belediyesinde park ve bahçelerin 
sayısı verilmiş, 13 büyükşehir belediyesinde park ve bahçelerin sayısı verilmemiştir. 22 büyükşehir belediyesinde üye sayıları verilmiştir, 8 büyükşehir belediyesinde üye sayıları verilmemiştir.

Tablo 2. Büyükşehir Belediyelerinin Faaliyet Gösterdiği Spor Branşlarn

\begin{tabular}{|c|c|c|c|c|}
\hline $\begin{array}{l}\text { Sira } \\
\text { No }\end{array}$ & $\begin{array}{l}\text { Büyükşehir } \\
\text { Belediyeleri }\end{array}$ & $\begin{array}{l}\text { Faaliyet Gösterilen } \\
\text { Spor Dallanı }\end{array}$ & $\begin{array}{l}\text { Sporcu } \\
\text { Sayıları }\end{array}$ & $\begin{array}{l}\text { Antrenör } \\
\text { Sayıs1 }\end{array}$ \\
\hline 1 & Adana & 14 & - & 14 \\
\hline 2 & Ankara & 38 & - & 590 \\
\hline 3 & Antalya & 35 & - & 40 \\
\hline 4 & Aydın & 15 & - & - \\
\hline 5 & Balıkesir & 28 & - & 29 \\
\hline 6 & Bursa & 22 & - & 76 \\
\hline 7 & Denizli & 18 & - & 18 \\
\hline 8 & Diyarbakır & 7 & 817 & 7 \\
\hline 9 & Erzurum & 17 & - & - \\
\hline 10 & Eskişehir & 9 & - & - \\
\hline 11 & Gaziantep & 6 & - & - \\
\hline 12 & Hatay & 12 & - & - \\
\hline 13 & İstanbul & 36 & 66,983 & - \\
\hline 14 & İzmir & 35 & 35,000 & 380 \\
\hline 15 & Kahramanmaraş & 14 & - & 20 \\
\hline 16 & Kayseri & 6 & - & - \\
\hline 17 & Kocaeli & 10 & - & 20 \\
\hline 18 & Konya & - & - & - \\
\hline 19 & Malatya & 3 & - & - \\
\hline 20 & Manisa & 11 & - & - \\
\hline 21 & Mardin & - & - & - \\
\hline 22 & Mersin & 13 & - & - \\
\hline 23 & Muğla & 8 & - & - \\
\hline 24 & Ordu & 4 & 6,372 & 25 \\
\hline 25 & Sakarya & 23 & - & - \\
\hline 26 & Samsun & 11 & - & - \\
\hline 27 & Şanlıurfa & 18 & 2,234 & - \\
\hline 28 & Tekirdağ & - & - & - \\
\hline 29 & Trabzon & 18 & - & 15 \\
\hline 30 & Van & 12 & 490 & 7 \\
\hline
\end{tabular}

Tablo 2'de Büyükşehir belediyelerinin faaliyet gösterdiği spor branşları incelediğimizde 3 belediyenin bilgilerine ulaşılamamıştır. 8 belediyenin 1 ile 10 arası, 12 belediyenin 11 ile 20 arası, 3 belediyenin 21 ile 30 arası, 4 belediyenin 31 ile 40 arası branşta faaliyet gösterdiği gözükmektedir. Büyükşehir belediyelerinin 16 'sinda antrenör ve yine 24 'ünde sporcu sayıları net olarak verilmemiştir. 
Büyükşehir Belediyelerinin Sportif ve Rekreatif Hizmetlerinin Niteliklerinin İncelenmesi

Tablo 3. Büyükşehir Belediyelerinde Sporu Yöneten Birim

\begin{tabular}{|c|c|c|c|c|}
\hline Sira No & $\begin{array}{l}\text { Büyükşehir } \\
\text { Belediyeleri }\end{array}$ & $\begin{array}{l}\text { Sporu Yöneten } \\
\text { Birim }\end{array}$ & $\begin{array}{l}\text { Sporu Yöneten } \\
\text { Birim }\end{array}$ & $\begin{array}{l}\text { Yürüttüğü } \\
\text { Sportif } \\
\text { Projeler }\end{array}$ \\
\hline 1 & Adana & Gençlik ve Spor Hiz. Daire Bşk. & Üniversite Mezunu & 14 \\
\hline 2 & Ankara & $\begin{array}{l}\text { Basın Yayın ve Halkla } \\
\text { İlişkiler Daire Bşk. }\end{array}$ & Üniversite Mezunu & 38 \\
\hline 3 & Antalya & Gençlik ve Spor Hiz. Daire Bşk. & Üniversite Mezunu & 1 \\
\hline 4 & Aydın & Gençlik ve Spor Hiz. Daire Bşk. & - & - \\
\hline 5 & Balıkesir & Kültür ve Sos. İşler Daire Bşk. & - & 3 \\
\hline 6 & Bursa & $\begin{array}{l}\text { Basın Yayın ve Halkla } \\
\text { İlişkiler Daire Bşk. }\end{array}$ & $\begin{array}{l}\text { Beden Eğitimi ve } \\
\text { Spor Böl. }\end{array}$ & 53 \\
\hline 7 & Denizli & Sosyal Hizmetler Daire Bşk. & Üniversite Mezunu & - \\
\hline 8 & Diyarbakır & Gençlik ve Spor Hiz. Daire Bşk. & - & - \\
\hline 9 & Erzurum & Kültür ve Sos. İşler Daire Bşk. & $\begin{array}{l}\text { Beden Eğitimi ve } \\
\text { Spor Böl. }\end{array}$ & - \\
\hline 10 & Eskişehir & Gençlik ve Spor Hiz. Daire Bşk. & - & - \\
\hline 11 & Gaziantep & Gençlik ve Spor Hiz. Daire Bşk. & Üniversite Mezunu & - \\
\hline 12 & Hatay & Kültür ve Sos. İşler Daire Bşk. & Üniversite Mezunu & 2 \\
\hline 13 & İstanbul & $\begin{array}{l}\text { Spor Aş.- Destek Hizmetleri } \\
\text { Daire Bşk. }\end{array}$ & Üniversite Mezunu & 19 \\
\hline 14 & İzmir & Kültür ve Sos. İşler Daire Bşk. & Üniversite Mezunu & - \\
\hline 15 & Kahramanmaraş & $\begin{array}{l}\text { Kültür, Turizm ve Spor } \\
\text { Daire Bşk. }\end{array}$ & Üniversite Mezunu & 2 \\
\hline 16 & Kayseri & Spor A.Ş. & Üniversite Mezunu & - \\
\hline 17 & Kocaeli & Gençlik ve Spor Hiz. Daire Bşk. & Üniversite Mezunu & 23 \\
\hline 18 & Konya & Gençlik ve Spor Hiz. Daire Bşk. & Üniversite Mezunu & - \\
\hline 19 & Malatya & $\begin{array}{l}\text { Kültür, Turizm ve Sosyal } \\
\text { İşler Daire Bşk. }\end{array}$ & - & - \\
\hline 20 & Manisa & Sosyal Hizmetler Daire Bşk. & - & - \\
\hline 21 & Mardin & $\begin{array}{l}\text { Kültür, Turizm ve Sosyal } \\
\text { İşler Daire Bşk. }\end{array}$ & Üniversite Mezunu & - \\
\hline 22 & Mersin & Gençlik ve Spor Hiz. Daire Bşk. & - & 13 \\
\hline 23 & Muğla & $\begin{array}{l}\text { Kültür, Turizm ve Spor } \\
\text { Daire Bşk. }\end{array}$ & Üniversite Mezunu & 12 \\
\hline 24 & Ordu & $\begin{array}{l}\text { Gençlik ve Spor Hiz. } \\
\text { Daire Bşk. }\end{array}$ & $\begin{array}{l}\text { Beden Eğitimi ve } \\
\text { Spor Böl. }\end{array}$ & - \\
\hline 25 & Sakarya & Gençlik ve Spor Hiz. Daire Bşk. & $\begin{array}{l}\text { Beden Eğitimi ve } \\
\text { Spor Böl. }\end{array}$ & 8 \\
\hline 26 & Samsun & Kültür ve Turizm Daire Bşk. & Üniversite Mezunu & 8 \\
\hline 27 & Şanlıurfa & Gençlik ve Spor Hiz. Daire Bşk. & Üniversite Mezunu & 16 \\
\hline 28 & Tekirdağ & Kültür ve Sos. İşler Dairebşk. & - & - \\
\hline 29 & Trabzon & Gençlik ve Spor Hiz. Daire Bşk. & $\begin{array}{l}\text { Beden Eğitimi ve } \\
\text { Spor Böl. }\end{array}$ & - \\
\hline 30 & Van & Kültür ve Sos. İşler Daire Bşk. & Üniversite Mezunu & 13 \\
\hline
\end{tabular}


Tablo 3'e göre 19 büyükşehir belediyesinde spor ile ilgili daire başkanlığın olduğu diğerlerinde farklı daire başkanlıkları ile olduğu yönetildiği görülmektedir. 15 Büyükşehir belediyesinde yürütülen herhangi bir proje görülmemektedir. Yine 8 Büyükşehir belediyesinde birim yöneticisinin bilgileri verilmemektedir.

\section{Tartışma ve Sonuç}

Büyükşehir belediyelerinin stratejik planlarının sportif faaliyetlerine yönelik incelenmesi amacı ile genel olarak aşağıda belirtilen amaçlar ve hedefler ile ilgili sonuçlar ortaya çıkmıştır. Bu çalışmada belirtilen amaçların bu yönü ile özellikle spor ile ilgili hizmet ve yatırımların stratejik planlarda yer alması önem arz etmektedir. Hedefler boyutunda ise; yeşil alan ve park yapımı, spor alanları oluşturmak, rekreasyon alanları oluşturmak, öğrencilerin sosyal yaşamlarını desteklemek, sportif etkinlikler düzenlemek, yürüyüş yolu yapmak, bisiklet yolu yapmak, spor salonu inşa etmek, yüzme havuzu yapmak, spor kulüplerine yardım etmek, çocuk oyun ve park alanları oluşturmak, halkın sportif etkinlere katılımını sağlamak, yaz spor okulları düzenlemek, yaz kampları düzenlemek ve engelli bireylere yönelik spor eğitimi verilmesi stratejik planda yer almaktadır.

Tablo 1 incelendiğinde büyükşehir belediyelerinin tesis sayıları gösterilmektedir. Yapılan araştırmaya göre illerin nüfuslarına göre tesis sayılarının karşılaştırılmasına baktığımızda; 26 büyükşehir belediyesinde salon ve tesis sayısı verilirken, 4 Büyükşehir belediyesinde verilmemiştir.

İstanbul 15.519.267 nüfusla 83 tesise ve bu da nüfusa oranla 186.979 kişiye 1 tesis, Ankara 5.639.067 nüfusla 38 tesise ve bu da nüfusa oranla 148.396 kişiye 1 tesis, İzmir 4.367.251 nüfusla 11 tesise ve bu da nüfusa oranla 397.022 kişiye 1 tesis, Bursa 3.056.210 nüfusla 15 tesise ve bu da nüfusa oranla 203.747 kişiye 1 tesis, Antalya 2.511 .700 nüfusla 3 tesise ve bu da nüfusa oranla 837.233 kişiye 1 tesis, Adana 2.237.940 nüfusla 92 tesis ve buda nüfusa oranla 24.325 kişiye 1 tesis, Şanlıurfa 2.073.614 nüfusla 7 tesis ve buda nüfusa oranla 296.230 kişiye 1 tesis Gaziantep 2.069.364 nüfusla 55 tesis ve buda nüfusa oranla 37.624 kişiye 1 tesis, Kocaeli 1.953 .035 nüfusla 44 tesise ve buda nüfusa oranla 44.387 kişiye 1 tesis, Mersin 1.840.425 nüfusla 14 tesise ve buda nüfusa oranla 131.458 kişiye 1 tesis, Diyarbakır 1.656.353 nüfusla 9 tesise ve buda nüfusa oranla 184.039 kişiye 
1 tesis, Hatay 1.628.894 nüfusla7 tesise ve buda nüfusa oranla 232.699 kişiye 1 tesis, Manisa 1.440.611 nüfusla 4 tesise ve buda nüfusla oranla 360.152 kişiye 1 tesis, Kayseri 1.407.409 nüfusla 15 tesise ve buda nüfusla oranla 93.827 kişiye 1 tesis, Samsun 1.348 .542 nüfusla 4 tesise ve buda nüfusla oranla 337.135 kişiye 1 tesis, Balıkesir 1.228.620 nüfusla 1 tesise ve buda nüfusa oranla 1.228.620 Kişiye 1 tesis, Kahramanmaraş 1.154.102 nüfusla 16 tesis ve buda nüfusa oranla 72.131 kişiye 1 tesis, Van 1.136 .757 nüfusla 5 tesis ve buda nüfusa oranla 227.351 kişiye 1 tesis, Aydın 1.110.972 nüfusla 1 tesis ve buda nüfusa oranla 1.110 .972 kişiye 1 tesis, Denizli 1.037.208 nüfusla 29 tesis ve bu da nüfusa oranla 35.765 kişiye 1 tesis, Sakarya 1.029.650 nüfusa oranla 9 tesis ve bu da nüfusa oranla 114.405 kişiye 1 tesis, Muğla 983.142 nüfusla 9 tesis ve bu da nüfusa oranla 109.238 kişiye 1 tesis, Trabzon 808.974 nüfusla 10 tesis ve bu da nüfusa oranla 80.897 kişiye 1 tesis, Malatya 800.165 nüfusla 18 tesis ve bu da nüfusa oranla 44.453 kişiye 1 tesis, Erzurum 762.062 nüfusla 12 tesis ve bu da nüfusa oranla 63.505 kişiye 1 tesis, Ordu 754.198 nüfusla 7 tesis ve bu da nüfusa oranla 107.742 kişiye 1 tesis oranına sahiptir. Yapılan çalışmada verilen spor tesisi sayılarının oldukça az olduğu görülmektedir. Nüfusa oranla da kişi sayıları karşılaştırıldığında kentlerde yaşayan bireylerin spor ihtiyacını karşılayacak nitelikte olmadığı görülmektedir. Spor tesisi kavramının kentlerin kültürünün unsurları göz önünde bulundurularak yapısına uygun bir şekilde ergonomik olarak inşa edilmesi ve işletilmesi gerektiği görülmektedir. Benzer bir çalışmada Antalya ve Aydın illerinde spor tesislerinin eksikliğine vurgu yapmaktadır (Gökdoğan, 2007). Yine Okçi ve diğ. (2009) tarafından yapılan çalışmada spor tesislerinden halkın yararlanma düzeyleri araştırılmış ve spor tesislerinin sayılarının az olduğu kişilerin bu tesislerden yararlanma düzeylerinin $\% 50$ olduğu bunun sebebi olarak da istedikleri zaman spor yapamadikları ve ikamet ettikleri yerlere olan uzaklıkları ve bunun yerine özel salonlara gittikleri, tesis çalişanlarının ve temizliğin yeterli olmadığı belirtilmiştir. Esenkaya (2010)' a göre yaptığ 1 çalışmada belediyelerin spor hizmetlerini sunarken hedef kitle olarak halkın bütün kesiminin (çocuk, genç, bay, bayan, yaşlı ve engelli) dikkate almalı, tesislerin yapımı ve işletimi konusunda halkın beklenti ve ihtiyaçlarını göz önünde tutması gerektiğini belirtmiştir. Belediyelerin sundukları spor hizmetlerinin tanitım ve duyurularını etkin olarak yapmaları gerektiği ayrıca spor tesisleri bünyelerinde halkın taleplerini 
dile getirebileceği danışma birimleri oluşturması gerektiğini vurgulamıştır. Bu unsurlar benzer şekilde Avrupa Kentli Halkları Deklarasyonunda dile getirilmiş hususlardır (Ekenci, 2012). Sporun yaygınlaştırılmasında hayati önem taşıyan spor tesislerinin belli bir politika çerçevesinde (hem yapım aşamasında hem de işletme aşamasında) ele alınması gerekmektedir (Ayan, 2002). Farklı bir görüş ise Türkiye'de toplumun büyük bir bölümü halen ihtiyaç duyduğu spor hizmetlerinin devlet eliyle yürütülmesini beklemektedir. Bu durum arz talep dengesi gereği sporun toplumda yaygınlaştırılmasını olumsuz yönde etkilemektedir (Can ve diğ., 2000).

Tablo 1 incelendiğinde büyükşehir belediyelerinin açık rekreatif alanları (park ve bahçelerin) nüfusa göre incelendiğinde 17 büyükşehir belediyesinde park ve bahçelerin sayısı verilirken, 13 büyükşehir belediyesinde park ve bahçelerin sayısı verilmemiştir. Çalışmamızdan elde edilen sonuçlara göre kentlerin alanlarının park ve rekreatif alanlarının yetersiz olduğu görülmektedir. Yapılan bir çalışmada kentsel yaşam kalitesinin ölçülmesi açısından rekreatif etkinlik alanı olarak çocuk parkları, semt sahaları ve yeşil alanların önemi araştırılmış olup kişi başına düşen büyüklüklerinin yeterli olduğu, bunun yanında kullanım sürelerinin 3-4 ay gibi düşük seviyede olduğu gözlemlenmiştir (Pepe ve diğg., 2009). Sportif ve açık alan rekreatif tesis sayısının artırılması, toplumda sportif düzeyin artırılması, eğitim ve sağlık kalitesi, modern yaşam alanları, zihinsel ve fiziksel engelli vatandaşlar için hizmetler, rekreasyon alanlarının geliştirilmesi gibi amaçlar stratejik planda yer aldığı görülmektedir (Öztaş ve Zengin, 2008). Yerel yönetimlerin saha ve tesis yatırımlarının özellikle kitleye ve rekreatif spor tesislerine yönelik olarak çeşitlilik kazanması önemlidir (Hoye ve diğ., 2015; Yıldız, 2018).

Tablo 2 incelendiğinde büyükşehir belediyelerinin spor branşı ve sporcu sayılarına göre bakıldığında; İstanbul 36 branşta 66,896 sporcu, Ankara 38 branşta 78.000 sporcu, İzmir 4.367 .251 nüfusa göre 35 branşta 35.000 sporcu, Bursa 22 branşta 85.000 sporcu, Antalya 35 branşta sporcu sayısına ulaşılamadı. Konya branş ve sporcu sayısına ulaşılamadı. Adana 14 branşta 4000 sporcu, Gaziantep 6 branşta sporcu sayısına ulaşılamadı. Şanlıurfa 18 branşta 2234 sporcu, Kocaeli 10 branşta 35000 sporcu, Mersin 13 branşta sporcu sayısına ulaşılamadı. Diyarbakır 7 branşta 817 sporcu, Hatay 12 branşta sporcu sayısına ulaşılamadı. Manisa 11 branşta sporcu 
sayısına ulaşılamadı. Kayseri 6 branşta sporcu sayısına ulaşılamadı. Samsun 11 branşta sporcu sayısına ulaşılamadı. Balıkesir 28 branşta sporcu sayısına ulaşılamadı. Kahramanmaraş 14 branşta sporcu sayısına ulaşılamadı. Van 12 branşta 490 sporcu, Aydın 15 branşta sporcu sayısına ulaşılamadı. Tekirdağ branş ve sporcu sayısına ulaşılamadı. Denizli 18 branşta sporcu sayısına ulaşılamadı. Sakarya 23 branşta 10.000 sporcu, Muğla 8 branşta sporcu sayısına ulaşılamadı. Eskişehir 9 branşta sporcu sayısına ulaşılamadı. Mardin branş ve sporcu sayısına ulaşılamadı. Trabzon 18 branşta 13.000 sporcu, Malatya 3 branşta sporcu sayısına ulaşılamadı. Erzurum 17 branşta 25.000 sporcu, Ordu 4 branşta 6372 sporcu ile belediye spor kulüplerinde aktif olarak spor yaptığı görülmektedir.

Tabloda 2'de sporcu sayılarının ve faaliyet gösterilen spor dalının s1nırlı sayılarda olduğu ve yerel yönetimlerin spor dallarına yeteri kadar yatırım yapmadığı görülmektedir. Ersöz ve Arun (2019)'a göre tarafından yapılan bir çalışmada ülkemizde erkek nüfusun $\% 8^{\prime}$ inin, kadın nüfusun $\% 4^{\prime}$ ünün toplam nüfusun ise \%6'sinın sporcu lisansına sahip olduğu görülmektedir. Lisansı daha çok çocuk, genç ve yetişkin kesimin çıkardığı göz önünde bulundurularak 10-44 yaş grubunun nüfusuna sporcu lisanslarını oranladığımızda ise erkek nüfusun $\% 14^{\prime}$ ünün, kadın nüfusun $\% 8^{\prime}$ inin toplam nüfusun ise \%11' inin sporcu lisansına sahip olduğu görülmüştür. Ülkedeki nitelikli sporcu sayısının ve kulüp sayısının artırılması ülke sporunun geleceği açısından son derece önemlidir. Belediye ve kamu tarafından yürütülen spor kulüplerinin niteliklerinin artırması bu açıdan hayatidir.

Tablo 2'de büyükşehir belediyelerinin 17'sinde antrenör sayıları verilmiş diğerlerinin verilerine ulaşılamamıştır. Toplanan verilerden elde edilen sonuçlara bakıldığında veri sisteminin çok düzensiz olduğu tespit edilmiştir. Büyükşehir belediyelerinin antrenör sayılarının yetersiz olduğu görülmektedir. Muhtemelen Gençlik ve Spor Bakanlığı ve/veya Halk Eğitimi Merkezi müdürlüğünden antrenör ihtiyacının karşılandığı düşünülmektedir. Büyük şehir belediyelerinin personel istihdam etme konusunda sorunlarının olduğu ve farklı statülerde antrenör ya da eğitmen istihdam ettikleri bilinmektedir. Buna ek olarak çalıştırılan personelin özlük hakları alanında sorun yaşadıkları bilinmektedir. Özellikle Ankara 
Büyükşehir belediyesinde yaklaşık yirmi yıldır "ek ders ve araştırma saatine" dayalı olarak ücretlendirilen sözleşmeli personel olduğu bilinmektedir. Ayrıca 4857 sayılı iş kanuna göre kamuda istihdam modelleri haricinde personel istihdam edilmemesi konusunda kesinlik bulunmaktadır. Esenkaya (2010) yılında spor tesislerinin kurulumu, işletilmesi ve kullanımının yaygınlaştırılması konusunda beden eğitimi ve spor bölümlerinden mezunların istihdam edilmesinin gerektiğinden bahsetmektedir. Buna ek olarak genç istihdamının artırılması konusunda spor sektörü önemli bir kalkınma aracı olarak kullanılmalıdır (Mumcu, Karakullukçu ve Karakuş, 2019).

Tablo 3 incelediğimizde büyükşehir belediyelerinde sporu yöneten birimlerin il bazında bakıldığında; 19 büyükşehir belediyesinde spor ile ilgili daire başkanlığın olduğu diğerlerinde farklı daire başkanlıkları ile sporun yönetildiği görülmektedir.

Bu durum 2008 yılında yapılan Spor Şurası'nda "Yerel Yönetimlerin gelişmiş ülkeleri örnek alarak illerde spor ve rekreasyon birimleri kurulmalıdır" şeklinde yer almaktadır (Spor Şurası, 2008). Büyükşehir belediyelerinin spor hizmetlerini halka layı̆̆ı ile ulaştırabilmesi halkın istek ve ihtiyaçlarına göre plan ve program yapabilmesi, spor özelinde ayrı bir yapılanmayı gerekli kılmaktadır. Nitekim büyükşehir belediye kanununda spor ihtisas komisyonunun kurulması zorunluluğu getirilmiştir. Fakat böyle bir komisyonun genellikle kurulmadığı onun yerine birçok belediyenin spor hizmetleri şube müdürlükleri kurarak spor hizmetlerinin bu müdürlükler aracılığı ile yürüttükleri görülmektedir. Oysaki ihtisas komisyonları spor hizmetlerinin yürütülmesinde sadece yürütme organı olarak değil aynı zamanda halkın taleplerinin belirlenmesine, istek ve ihtiyaçlarının tek bir elden tespit edilerek bu yönde politika ve uygulamaların geliştirilmesine imkân sağlayacaktır (Yücel ve diğ., 2016). Karakuş ve Sunay (2000)'a göre belediyelerin karar mercilerinin, sporun kitlelere yaygınlaştırılması konusunda yerel yönetimlerin öneminin farkında olduğunu ancak çok çeşitli görevler yüklenmiş olan belediyelerin, spor ve spor yönetimi konusunda oluşmuş bir geleneğinin bulunmadığını ve belediyelerin spor işlerinin sevk ve idaresinin genellikle "Eğitim-Kültür Müdürlükleri” aracılığı ile yürütüldüğünü belirterek belediyelerin spor hizmet- 
lerinin ve bu çerçevede kitle sporunun geliştirilmesinde etkin bir yer alabilmesi için öncelikle belediyelerde mesleki eğitim almış spor yöneticilerinin istihdam edilmesi ve bu yöneticilerin amaca yönelik olarak görev yapabilmesi için belediye bünyesinde spor biriminin kurulması ve kurumlaşması gerektiğini ifade etmişlerdir.

Tablo 3 incelediğinde verilen bu bilgiler doğrultusunda sportif faaliyetlerin yönetilmesinde Spor Bilimleri Fakültesi mezunu olmayan idarecilerinde olduğu görülmekte olup yapılan proje faaliyet ve sportif araştırmaların yönlendirilmesinde aksaklıklara sebebiyet verebileceği düşünülmektedir.

Sporu yöneten kurumun niteliği ve sporu yöneten birimin sorumlusu olarak görev yapan bireylerin hizmet verilen alanda eğitim almış kişilerden istihdam edilmesi gerekliliği görülmektedir. Yerel yönetimler sporla ilgili kadrolarını “Beden Eğitimi ve Spor Yüksek Okulu Öğretmenlik, antrenörlük ve spor yöneticiliği bölümlerinden mezun kişi veya kişilerden oluşturmalıdır (Sinopluoğlu, 2010). Kurtipek (2017)'e göre belediyelerde gençlik ve spor hizmetlerini yürüten idarecilerin spor eğitimi almış ve alandan gelmiş olmasına dikkat edilmesi gerekmektedir.

Yine diğer bir araştırmada spor endüstrisi içerisinde yer alan örgütler, iletişim becerisi yüksek, takım araştırmasına uygun, planlama ve organizasyon becerisi olan bireylere ihtiyaç duymaktadır. Yerel yönetimlerde görev alacak personelin spor eğitimi almış kişilerden olması ise önemli bir etken olarak görülmektedir (Yıldız, 2018).

Tablo 3 incelendiğinde büyükşehir belediyelerinin yürütmüş olduğu sportif faaliyetlerinin sayıları ve nüfusların göre değerlendirdiğimizde; Büyükşehir belediyelerinde sportif projelerin oranlarının oldukça düşük seviyede olduğu görülmektedir. Uluslararası düzeyde projeler ve ortaklıkların da yapılmadı görülmektedir. Araştırmadan elde edilen sonuçlara göre spor projelerine çok fazla önem verilmediği görülmektedir. Özellikle yerel yönetim birimlerinin proje birimlerinin spor alanında yeterince araştırma yapmadığı görülmektedir. AB Spor Plus Projeleri başlığında yerel yönetimlerin pek çok iş birliği projesi olmasına rağmen, bu alanda da hiçbir belediyenin yürüttüğü $\mathrm{AB}$ projesi olmaması oldukça çarpıcı bir sonuçtur. Yüzgenç'in (2016) yılında yaptı̆̆ 1 araştırmada da benzer eksiklikler tespit edilmiştir. Sportif proje araştırmalarına çok fazla ağırlık verilmediği 
gözükmektedir. Halk ile belediye arasında bir iletişim aracı olarak görülmesi gereken spor hizmetlerinin etkin bir şekilde kullanılması, halk ve belediyeler arasındaki ilişkiyi kuvvetlendirip halkın kamu hizmetlerine olan güven duygusunu arttıracaktır. Bunun yanında özellikle gençlere yönelik projeler spor hizmetlerinden yararlanması ve algılanan hizmet kalitesini artıracaktır (Aligül ve diğ., 2019).

Toplumsal bir kurum olma özelliği taşıyan sporun geniş kitlelere yayılması herkesin spor imkânlarından yararlanması, sporun bireye ve topluma kazandıracağı değerlerle insan ve toplum mutluluğunun sağlanması, yerel yönetimlerin spor politikaları ve yatırımlarına gereken önemi vermeleri ile mümkün olacaktır (Karakuş ve diğ., 2000). Halkın aktif spor etkinliklerine olan ilgisinin artırılması, sağlıklı yaşam açısından sporun öneminin ortaya konulması ve spor yapma bilincinin oluşturulması için belediyeler ellerinde bulunan kitle iletişim araçlarını aktif olarak kullanmalı; tabela, pankart vb. kitle iletişim araçlarını kullanarak, çeşitli slogan ve bilgilendirici unsurlarla hareketli yaşamın önemi anlatılmalıdır. Halkı hareketli yaşama ve spor yapmaya özendiren çeşitli organizasyonlar düzenlemeli organizasyonlara halkın aktif katılımını sağlamalıdır (Esenkaya, 2010). Yerel yönetimlerin spora ayırdıkları kaynakların amatör spor kulüplerine destekten çok daha fazla çocuk ve gencin katılımını sağlayacak yaz ve kış spor okulları açmak ve halkın spora yüksek katılımını sağlayacak organizasyonlar düzenlemesi gerektiği düşünülmektedir (Sinoğluoğlu, 2010). Kurumlar serbest zaman aktivitelerine ihtiyaç duyan vatandaşlara hizmet götürülmesi konusunda heyecan duyarlarsa bu programlar onlara maddi ve siyasi anlamda önemli faydalar sağlayabilir. Ayrıca bu kuruluşlar ve yerel anlamdaki önemli kişiler, rekreasyon programlarının başarıya ulaşmasında katkıda bulunabilirler. Böylelikle herkes için yararlı olabilecek bu aktivitelerin gelişmesi ve sürdürülebilirliği gerçekleşmiş olur (Tony ve diğ., 2006).

Sonuç olarak sporun yönetimi genellikle büyükşehir belediyesinin teşkilat şemasında yer alan gençlik ve spor dairesi ya da kültür ve sosyal işler gibi diğer birimlerin altında yer almaktadır. Bunlardan farkı olarak İstanbul ve Kayseri illeri örneklerinde olduğu gibi spor faaliyetleri şirketler üzerinden yönetilmektedir. Burada tüm birimlerde spor dairelerinin kurulması ya da sporu yönetecek şirket yapılarının kurulmasının gerekliliği ortaya çıkmaktadır. Sporu yöneten birimin sorumlularının beden eğitimi 
ve spor alanlarından gelenlerin sayısının çok düşük olduğu görülmektedir. Yalnızca beş büyükşehir belediyesinin spor sorumlusu spor alanından mezun olan yöneticiler tarafından yönetilmektedir.

Sportif projeleri incelendiğinde pek çok büyükşehir belediyesinin hali hazırda yürüttügü spor projesi bulunmamaktadır. Yürütülen projelerin birkaç örneği incelendiğinde küçük yerel faaliyetler olduğu görülmektedir. Ulusal ve uluslararası büyüklükte spor projesi yürüten büyükşsehir belediyesine rastlanmamıştır.

Açık alan rekreasyon alanlarının ve spor tesislerinin pek çoğunun konumları, yerleri ve nitelikleri büyükşehir belediyelerinin kurumsal internet sayfalarında net olarak verilmemektedir. Bu da halkın hizmetlere ulaşması ve erişmesi açısından eksikliklerin olduğu sonucunu doğurmaktadır. Yine büyükşehir belediyelerinin sportif faaliyetlerine katılan üye sayılarının nüfusa göre oldukça düşük olduğu görülmektedir. Sportif faaliyetlere ulaşım ve erişim konusunda eksikliklerden kaynaklandığı düşünülmektedir. Sportif faaliyetlerin ve hizmetlerinin verildiği alanlarda kalitenin arttırılması ve halkın en iyi şekilde hizmetlerden yararlanması amacıyla şu öneriler yapılabilir; büyükşehir belediyeleri spor hizmetlerini düzenlerken ilgili kamu kurum ve kuruluşlarıyla, üniversitelerle, dernek ve çeşitli sivil toplum kuruluşlarıyla birlikte hareket etmelidir.

Sporun sadece tesisleşmeden ibaret olmaması amacıyla kalıcı bir spor politikası üretilmesi gerekmektedir. Bununda tesisleşme, alt-yapı, amatör spor, herkes için spor, sporun sosyo-kültürel ve sosyo-ekonomik durumların etkileri göz önüne alınarak bütüncül bir yaklaşımla oluşturabilir. Büyük spor tesisleri oluşturmak yerine amatör spor ve herkes için sporu geliştirmekle birlikte spor işletme maliyetlerini de düşünerek küçük ölçekli ve etkin kullanılan tesisler yapılabilir. Özellikle Covid 19 salgını esnasında yapılan kısıtlamalar esnasında oluşan durumdan dolayı açık alanları tercih edilmesi, bu alanlarının imarının ne kadar önemli olduğunu göstermiştir.

Verilen hizmetlerin kalitesinin artırılması amacıyla günümüz iletişim ve haberleşme çağının gerekliliklerini yerine getirerek, verilen hizmetlerin erişimini ve ulaşılmasını kolaylaştırmak amacıyla web ve online hizmetlerini güncellemelidir. Örneğin Herkes İçin Spor Federasyonun geliştirdiği HisApp uygulamasına benzer bir mobil uygulamanın yerel spor hiz- 
metlerinin kalitesi arttırabilir. Özellikle sportif hizmetlere engelli bir bireyin erişimi kolay ve basit olmalıdır. Engelli vatandaşlarımızı hayata kazandırmak ve onların yaşamlarını zorlaştıracak engelleri kaldırmak için bu tür uygulamalar önemlidir. Denizli büyükşehir belediyesi tarafından, engelli çocukların da diğer sağlıklı çocuklar gibi kimsenin yardımı olmadan oynayabileceği özel açık rekreatif alan düzenlenmiştir. Sonuç olarak; ülke genelinde büyükşehir belediyelerini ve diğer yerel belediyeleri de kapsama dahil edecek "Spor İşletim Sistemi (SİS)" planı oluşturularak bütüncül bir yapı ile sporun tek elden elektronik altyapısının ve haritalandırmasının yapılması gerekmektedir. 


\title{
EXTENDED ABSTRACT
}

\section{Examination Of The Qualities Of Sports And Recreational Services Of Metropolitan Municipalities}

\author{
Hasan Erdem Mumcu - Bahadır Aligül - Ömür Fatih Karakullukçu \\ Yakup Paktaş \\ Tokat Gazi Osman Paşa University, Republic of Turkey Ministry of Youth and Sport, \\ Ankara Hacı Bayram Veli University
}

The aim of this study is to determine the place of sport and its scope in service of the metropolitan municipalities in Turkey. It is aimed to determine the deficiencies of an institution that produces services of this size locally in sports management and to make suggestions to eliminate these deficiencies. It is shed light on the implementation of sports services, which are considered to be lacking in local governments, by establishing a standard service policy. Sporty services and administrative structures of all existing metropolitan municipalities in Turkey were examined. Necessary data were obtained from the websites of the sports services provided by the metropolitan municipalities, by mail and petition. Findings were collected in accordance with the document analysis method and were interpreted by document analysis and comparison method. According to the results obtained from the findings, it is seen that the sports service units of metropolitan municipalities are not widely disseminated from the websites. In addition, data on sports services could not be reached in most of the metropolitan municipalities. It is observed that only five of the unit managers working in the units providing sports services have graduated from sports education departments. While decisions have been made regarding the necessity of conducting sports services through sports departments, it was observed that they operate under different departments in twelve metropolitan municipalities. In addition, only five of the department heads who are responsible for institution have received training in the field of sports, and the qualification of the director of the institution was not given in eight of them. While the design of sports areas as open and closed to meet the needs of cities and their distribution according to population is sup- 
ported by laws, it has been seen that the facilities and open spaces are insufficient in most of them. When the outdoor recreational areas (parks and gardens) are examined according to the population, the number of parks and gardens in seventeen metropolitan municipalities is given, while the number of parks and gardens in thirteen metropolitan municipalities is not given. In addition, the number of halls in four provinces, open spaces in eleven provinces and the number of members in eight provinces are not given. With this aspect of the objectives stated in this study, it is vital that services and investments related to sports exist in the strategic plans. In terms of goals; the strategic plan includes the construction of green areas and parks, creating sports areas, creating recreation areas, supporting the social life of students, organizing sports activities, walking paths, building a bicycle path, building a gym, building swimming pools, helping sports clubs, children's playgrounds and parks, establishing the participation of the public in sports activities, organizing summer sports schools, organizing summer camps and providing sports training for disabled individuals. It is seen that metropolitan municipalities have very few sports-oriented projects on a local and national basis and no projects in international areas. Although it is known that the people who will carry out the relevant sports activities should consist of trainers and experts equipped with the necessary qualifications in order for the public to receive quality service, it is seen that metropolitan municipalities have deficiencies in terms of creating employment in sports. While local sports clubs and their infrastructures are supported by laws, it has been observed that the number of athletes and the capacities of the sports branches in which they are active are low or lack of data. The number of sports branches in three provinces, the number of athletes in 24 provinces and the number of trainers in seventeen provinces could not be reached. The concept of sports facilities should be considered as important elements of the city culture, and it is thought that it should be built and operated ergonomically in accordance with the city's structure. When the number of people is compared with the population, it is seen that sports facilities are not qualified to meet the sports needs of the individuals living in the cities. It has been concluded that metropolitan municipalities had better improve their corporate internet and web-based visibility in sports / recreation areas in a way that will make the qualifications of the cities better and help the public to get better service. In order to increase the service quality, policies regarding both the employment of 
trained human resources and the administrative structure should be revised. The metropolitan municipalities' ability to deliver sports services to the public with dignity and their ability to plan and program according to the demands and needs of the people necessitates a separate structuring specific to sports. As a matter of fact, the necessity of establishing a sports expertise commission has been introduced in the metropolitan municipality law. However, it is seen that such a commission is generally not established, and instead, many metropolitan municipalities establish sports services departments and all sports services are carried out through these directorates. A data-based sports operating system is thought to contribute to the development of sports in terms of measuring the quality of the service provided and increasing its quality. It should be ensured that an infrastructure such as the sports operating system (SOS) will increase the quality of sports services of local government services and if necessary, this should be systematically expanded in all local government units. For example, a mobile application similar to the HisApp application developed by Sports for All Federation can increase the quality of local sports services. Especially, sports services should be easy for a disabled individual to access. Such practices are extremely important in order to bring our disabled citizens to life and to remove the obstacles that will make their lives difficult. A permanent sports policy should be produced in order that sports do not consist only of facilities. In this, establishment can be created with a holistic approach by taking into consideration the infrastructure, amateur sports, sports for all, the effects of sport's socio-cultural and socioeconomic conditions. Instead of establishing large sports facilities, smallscale and effectively used facilities can be built, considering sports operating costs, as well as developing amateur sports and sports for everyone. Especially, choosing open areas due to the situation that occurred during the restrictions made during the COVID-19 epidemic has shown how important the zoning of these areas is. With the aim of examining the strategic plans of metropolitan municipalities for their sportive activities, the results related to the following purposes and targets in general have emerged. 


\section{Kaynakça / References}

Aligül, B., Mumcu, H.E., Özleyen, A., ve Mumcu, N. (2019). Investigation of perceived service quality of youth centers. Uluslararast Rekreasyon ve Spor Bilimleri Dergisi, 3(1), 5-15.

Altuntaş, T., Sertbaş, K., Gönener, U., Uzuner, M., Gönener, A., Bahadır, T. (2020). Yerel yönetimlerde fiziksel hareketin sürdürülebilirliğini destekleyen KOBIS (Kocaeli bisikletli ulaşım sistemi) projesinin yönetim ve uygulama süreçlerinin incelenmesi. Sinop Üniversitesi Sosyal Bilimler Dergisi, 4 (1), 277-296.

Ankara Büyükşehir Belediyesi. (2020). Sosyal Hizmetler. 08.06.2020 tarihinde https://ankara.bel.tr/sosyal-hizmetler/genclik-hizmetleri adresinden erişildi.

Ankara Büyükşehir Belediyesi. (2020). Aile Yaşam Merkezleri. 08.06.2020 tarihinde https://ankara.bel.tr/sosyal-hizmetler/aile-yasam-merkezleri adresinden erişildi.

Ankara Büyükşehir Belediyesi. (2020). Sosyal Hizmetler. 08.06.2020 tarihinde https://direct.ankara.bel.tr/sosyal-hizmetler/genclik hizmetleri/genclik-merkezleri adresinden erişildi.

Adana Büyükşsehir Belediyesi. (2020). Stratejik Plan. 08.06.2020 tarihinde https://www.adana.bel.tr/panel/uploads/stratejikplani v/files/2020-2024adana-buyuksehir-belediyesi-stratejik-plani.pdf adresinden erişildi.

Adana Büyükşehir Belediyesi. (2020). Halka Bilinçli Spor Olanağı. 08.06.2020 tarihinde https://www.adana.bel.tr/haber/halka-bilincli-spor-olanagiadresinden erişildi.

Antalya Büyükşehir Belediyesi. (2020). Spor Hizmetleri. 08.06.2020 tarihinde https://https://www.abbsporhizmetleri.com/spor/adresinden erişildi.

Arslan, E., Ünlü, H., Çelebi, M. (2011). Yerel yönetimlerin spora bakış açları ile spor programlarının sürdürülebilirliğinin incelenmesi. Balçova Belediyesi örneği. I. Uluslararast Spor Ekonomisi ve Yönetimi Kongresi

Atasoy, V. (1992). Türkiye'de mahalli idarelerin yapısı ve yeniden düzenlenmesi. Ankara: Türk Dünyası Araştırmaları Vakfı Yayınları, 10,48-49

Atasoy, B., Kuter, F.Ö. (2005). Küreselleşme ve spor. Uludağ Üniversitesi Eğitim Fakültesi Dergisi, 18(1), 11-22.

Aydın Büyükşehir Belediyesi. (2020). Spor Performans. 09.06.2020 tarihinde https://aydin.bel.tr/Content/images/raporlar/PERFORMANS\%20PROGRAMI/PERFORMANSPROGRAMI 2019.pdf adresinden erişildi.

Bahadır, T.K. (2019). Voleybolcularda duygusal zekâ ile örgütsel bağlllık ilişkisinin bazı değişkenler açısından incelenmesi. Manas Sosyal Araştırmalar Dergisi, 8(4), 3746-3763. 
Balıkesir Büyükşehir Belediyesi. (2020). Hizmet Şeması. 09.06.2020 tarihinde https://www.balikesir.bel.tr/kurumsal/organizasyon-semasi/genclik-ve-sporsube-mudurlugu adresinden erişildi.

Bursa Büyükşehir Belediyesi Spor. (2020). Spor Hizmetleri. 09.06.2020 tarihinde https://www.bursa.bel.tr/spor-cocuklarin-ayagina-gidiyor/haber/29084 adresinden erişildi.

Bursa Büyükşehir Belediyesi Spor. (2020). Spor Faaliyetleri. 09.06.2020 tarihinde https://www.bursa.bel.tr/buyuksehirle-spor-her-yerde/haber/29055 adresinden erişildi.

Bursa Büyükşehir Belediyesi Spor. (2020). Spor Her Yerde. 09.06.2020 tarihinde https://www.bursa.bel.tr/buyuksehirle-spor-her-yerde/haber/29055 adresinden erişildi.

Can, Y., Soyer, F. ve Güven, H. (2000). Spor hizmetlerinde verimliliği etkileyen faktörlerin değerlendirilmesi. 1.Gazi Beden Eğitimi ve Spor Bilimleri Kongresi. Ankara. Gazi Üniversitesi.

Çetin, H.N. (1986). Türkiye'de sporun yaygınlaştırılması. Yüksek Lisans Tezi. Gazi Üniversitesi. Sosyal Bilimler Enstitüsü.

Çevik, H. ve Demirci, S. (2012). Kamu politikası: Kavramlar, aktörler, süreç, modeller, analiz, karar verme. Bursa: Seçkin Yayıncılık. No.2,80-82

Denizli Büyükşehir Belediyesi. (2020). Spor Tesisleri. 09.06.2020 tarihinde https://www.denizli.bel.tr/Default.aspx?k=sportesisleri adresinden erişildi.

Denizli Büyükşehir Belediyesi. (2020). Yeşil Alan Projeleri. 09.06.2020 tarihinde https://www.denizli.bel.tr/Default.aspx?k=yesil-alan-projeleri adresinden erişildi.

Doğu, G., Kesim, Ü. ve Sivrikaya, Ö. (2002). Belediyelerin sporla ilgili işlevleri: Düzce Belediyesi örneği. Çă̆daş Yerel Yönetimler Dergisi, 11(2).

Diyarbakır Büyükşehir Belediyesi. (2020). Kültür Faaliyetleri. 09.06.2020 tarihinde http://www.diyarbakir.bel.tr/haberler/1950-kultur.html adresinden erişildi.

Diyarbakır Büyükşehir Belediyesi. (2020). Spor Faaliyetleri. 09.06.2020 tarihinde http://www.diyarbakir.bel.tr/haberler/1942-kultur.html adresinden erişildi.

Ekenci, G. (2012). Belediyeler 'herkes için spor' politikaları geliştirmelidir. Marmara Belediyeler Birliği, Marmara'da Birlik, 37(77), 30-31.

Ersöz, G. ve Arun, K. (2019). Spor Genel Müdürlüğü tarafından 2018 yılına kadar kaydı tutulan sporcu lisansı sayılarının kayılı nüfus bilgilerine göre analizi. 3.Uluslararası Sağhlk Bilimleri Kongresi, 24-26 Ekim 2019, Çanakkale.

Erzurum Büyükşehir Belediyesi. (2020). Stretejik Plan. 10.06.2020 tarihinde http://www.erzurum.bel.tr/DOSYA/stratejiplan2020.pdf adresinden erişildi. 
Erzurum Büyükşehir Belediyesi. (2020). Spor Tesisleri. 10.06.2020 tarihinde http://www.erzurumsporas.com.tr/tesisler/1/0/erzurum-da-bulunan-spor-tesisleri.html adresinden erişildi.

Eskişehir Büyükşehir Belediyesi. (2020). Stratejik Plan. 10.06 .2020 tarihinde https://www.eskisehir.bel.tr/dosyalar/stratejik plan/2020.pdf adresinden erişildi.

Esenkaya, A. (2010). Halkm yerel yönetimlerden spor hizmetleri konusunda beklentirleri: Konya örneği.Yüksek Lisans Tezi.Yök Ulusal Tez Merkezi

Fişek, K. (2003). Devlet politikası ve toplumsal yapıyla ilişkileri açısından spor yönetimi: Dünyada-Türkiye'de,.YGS Yayınları. No.1, 25-26

Gaziantep Büyükşehir Belediyesi. (2020). Stratejik Plan. 11.06.2020 tarihinde https://gaziantep.bel.tr/uploads/2020/07/2020-2024-stratejik-plan.pdf adresinden erişildi.

Gaziantep Büyükşehir Belediyesi. (2020). Spor Projeleri. 11.06 .2020 tarihinde https://www.gaziantep.bel.tr/tr/arama?q=spor adresinden erişildi

Gökdoğan D. (2007). Kahramanmaraş ilindeki öncelikli spor branşlarmmn tespiti ile bu branşlarn seçimine etki eden sebeplerin araştırlmast ve kitle sporunun yayg̨nlaşmast açısından değerlendirilmesi. Yüksek Lisans Tezi. Dumlupınar Üniversitesi. Sosyal Bilimler Enstitüsü.

Havuç, T., Sertbaş, K., Bahadır, T.K., Çutuk, S. ve Uzuner, M.E. (2020). Cimnastik sporcusu ailelerin duygusal zeka ve örgütsel bağlllkkları arasındaki ilişkinin incelenmesi. Spor ve Rekreasyon Araştrmalan Dergisi, 2(1),57-69.

Hoye, R., Smith, A.C., Nicholson, M. ve Stewart, B. (2015). Sport management: Principles and applications. 4 Edition. New York: Routledge.

İstanbul Büyüksşehir Belediyesi. (2020). Spor Faaliyetleri. 11.10.2020 tarihinde https://genclikspor.ibb.istanbul/ adresinden erişildi.

İstanbul Büyükşehir Belediyesi. (2020). Stratejik Plan. 11.06.2020 tarihinde https://www.ibb.istanbul/SitePage/Index/127 adresinden erişildi.

İstanbul Büyükşehir Belediyesi. (2020). Spor Projoleri. 11.06.2020 tarihinde http://www.istanbulbbsk.org/adresinden erişildi.

İstanbul Büyükşehir Belediyesi. (2020). Spor Tesisleri. 11.06.2020 tarihinde https://izcilik.ibb.istanbul/adresinden erişildi.

İstanbul Büyükşehir Belediyesi. (2020). Spor Envanteri. 11.06.2020 tarihinde https://www.istanbulsporenvanteri.com/adresinden erişildi.

İzmir Büyükşehir Belediyesi. (2020). Spor Projeleri. 11.06.2020 tarihinde https://www.izmir.bel.tr/tr/ProjeKategori/1330/4 adresinden erişildi. 
İzmir Büyükşehir Belediyesi. (2020). Spor Branşları. 11.06.2020 tarihinde https://www.dha.com.tr/spor/100-yilda-hedef-50-brans-50-bin-sporcu/haber1776995 adresinden erişildi.

İzmir Büyükşehir Belediyesi. (2020). Spor Tesisleri ve Etkinlikler. 11.06.2020 tarihinde https://www.izmir.bel.tr/tr/spor-ve-etkinlik-tesisleri/60/119 adresinden erişili.

Kahramanmaraş Büyükşehir Belediyesi. (2020). Stratejik Plan. 12.06.2020 tarihinde http://www.sp.gov.tr/upload/xSPStratejikPlan/files/ni5Lc+Kahramanmaras.Buyuksehir Belediyesi 2020-2024 Donemi Stratejik Plani.pdf adresinden erişildi.

Karakullukçu, Ö.F. ve Karaküçük, S. (2017). Leisure time habits of employees of ministry of justice according to the education level. Uluslararast Rekreasyon ve Spor Bilimleri Dergisi, 1(1), 5-12.

Karakuş, E. ve Sunay, H. (2000). Sporun kitlelere yaygınlaştırlmasında, yerel yönetimlerin yeri ve fonksiyonuna ilişkin Ankara İli Metropol ilçeleri belediye meclisi üyelerinin görüşleri. Gazi Beden Eğitimi ve Spor Bilimleri Dergisi, 3, 63-80.

Kayseri Büyükşehir Belediyesi. (2020). Sağllklı Yaşam ve Spor. 13.06.2020 tarihinde https://www.sporaskayseri.com.tr/icerikler/saglikli-yasam-yuruyusu adresinden erişildi.

Kayseri Büyükşehir Belediyesi. (2020). Spor Projeleri. 13.06 .2020 tarihinde https://www.sporaskayseri.com.tr/icerikler/haydi-beyler-spora adresinden erişildi.

Kayseri Büyükşehir Belediyesi. (2020). Spor Okulları. 13.06.2020 tarihinde https://www.sporaskayseri.com.tr/icerikler/spor-okullarimiz adresinden erişildi.

Kayseri Büyükşehir Belediyesi. (2020). Doğa Kampları 13.06.2020 tarihinde https://www.sporaskayseri.com.tr/icerikler/doga-kamplari adresinden erişildi.

Kocaeli Büyükşehir Belediyesi. (2020). Spor Hizmetleri. 13.06.2020 tarihinde https://www.kocaeli.bel.tr/tr/main/birimler/genclik-ve-spor-hizmetleridairesi-baskanligi/32 adresinden erişildi.

Konya Büyükşehir Belediyesi. (2020). Spor Hizmetleri. 13.06.2020 tarihinde https://www.konya.bel.tr/kurumsalayrinti4.php?id=214 adresinden erişildi.

Konya Büyükşehir Belediyesi. (2020). Spor Hizmetleri. https://www.konya.bel.tr/kurumsalayrinti4.php?id=214

Kurtipek, S. (2017). Metropoliten alan içerisindeki belediyelerin gençlik ve spor politikalarnm değerlendirilmesi. Doktora Tezi, Yök Ulusal Tez Merkezi 
Mersin Büyükşehir Belediyesi. (2020). Spor Hizmetleri. 14.06.2020 tarihinde https://www.mersin.bel.tr/genclik-spor-db adresinden erişildi.

Muğla Büyükssehir Belediyesi. (2020). Spor Hzimetleri. 14.06.2020 tarihinde https://www.mugla.bel.tr/birim/kultur-turizm-ve-spor-dairesi-baskanligi adresinden erişildi.

Muğla Büyükşehir Belediyesi. (2020). Spor Faaliyetleri. 14.06.2020 tarihinde https://www.mugla.bel.tr/uploads/sayfatr/ortaca_2015.pdf adresinden erişildi

Mumcu, H.E., Karakullukçu, Ö.F. ve Karakuş, M. (2019). Youth employment in the sports sector. OPUS Uluslararası Toplum Araştrmalan Dergisi, 11(18), 26492665.

Okçi, A., Çetinaslan, A., Başaran, Z. ve Erdal, R. (2009). Kocaeli IIlinde halkn spor tesislerinden yararlanma düzeyi: Uluslararası herkes için spor turizmi. Ankara:Nehir Matbaacllk, 127.

Ordu Büyükşehir Belediyesi (2020). Spor Hizmetleri. 15.06.2020 tarihinde http://www.ordu.bel.tr/Gençlik Spor adresinden erişildi.

Ordu Büyükşehir Belediyesi (2020). Spor Faaliyetleri. 15.06.2020 tarihinde http://www.ordu.bel.tr/Projeler/Planlanan-Projeler/1209 adresinden erişildi.

Öztaş, C. ve Zengin, E. (2008). Yerel yönetimler ve kültür hizmetleri. Sosyal Siyaset Konferanslarn Dergisi, 54, 155-180.

Özlü, K., Çeviker, A., Paktaş, Y., Mumcu, H. E., ve Kusan, O. (2020). Reflection of immoral and unethical sport events upon the society and mass media throughout history.

Pepe, K. ve Özdemir E. (2009). Kentsel yaşam kalitesi açısından rekreatif etkinlik alanı olarak çocuk parkları, semt sahaları ve yeşil alanların incelenmesi: Burdur ili çalışması. Uluslararası Herkes İçin Spor Turizmi, içinde (s.129) Ankara: Nehir Matbaacllik,

Sakarya Büyükşehir Belediyesi (2020). Spor Hizmetleri. 15.06.2020 tarihinde https://www.sakarya.bel.tr/tr/Daire-Baskanligi/genclik-ve-spor-hizmetleridairesi-baskanligi/ 135 adresinden erişildi.

Sakarya Büyükşehir Belediyesi(2020). Spor Faaliyetleri. 15.06.2020 tarihinde https://www.sakarya.bel.tr/tr/Proje/2020-dunya-dag-bisikleti-maratondunya-sampiyonasi/140 adresinden erişildi.

Sakarya Büyükşehir Belediyesi(2020). Spor Projeleri. 15.06.2020 tarihinde https:/www.sakarya.bel.tr/tr/Proje/aycicegi-vadisi-ve-bisiklet-adasi/291 adresinden erişildi.

Samsun Büyükşehir Belediyesi (2020). Spor Hizmetleri. 16.06.2020 tarihinde https://www.samsun.bel.tr/samsun-haber/spor adresinden erişildi. 
Samsun Büyükşehir Belediyesi (2020). Spor Faaliyetleri. 16.06.2020 tarihinde https://samsun.bel.tr/samsun-haber/spor adresinden erişildi.

Spor İstanbul (2020). Spor Faaliyetleri. 17.06.2020 tarihinde http://spor.istanbul/faaliyetler/uluslar-arasi-istanbul-salon-atletizm-kupasi.aspx adresinden erişildi.

Sinopluoğlu, M.B. (2010). Yerel Yönetimlerin sporun kitlelere yaylması etkisi: Eskişehir İli örneği. Yüksek Lisans Tezi, Yök Ulusal Tez Merkezi

T. C. Başbakanlık Gençlik ve Spor Genel Müdürlüğü. (2008). Spor şurası.

Şanlıurfa Büyükşehir Belediyesi (2020). Spor Hizmetleri. 16.06.2020 tarihinde https://www.sanliurfa.bel.tr/birim/24/485/genclik-ve-spor-hizmetleri-dairesibaskanligi adresinden erişildi.

Şanluurfa Büyükşehir Belediyesi (2020). Spor Faaliyetleri. 16.06.2020 tarihinde http://www.sanliurfa.bel.tr.icerik/57/4/spor-merkezleri adresinden erişildi.

Tekirdağ Büyükşehir Belediyesi (2020). Spor Faaliyetleri. 16.06.2020 tarihinde http://www.tekirdag.bel.tr/content/WebSource/file/faaliyet raporu/2019 yili idare faaliyet raporu.pdf adresinden erişildi.

Mobley, T. A. (2006). Yerel yönetimlerin halkn rekreasyon ve park ihtiyaç ve hizmetlerini karşımadaki rolï.

Tütüncü, Ö., Aydin, İ., Küçükusta, D., Avcı, N., ve İlkay, T. A. Ş. (2011). Üniversite öğrencilerinin rekreasyon faaliyetlerine katilımın etkileyen unsurların analizi. Spor Bilimleri Dergisi, 22(2), 69-83.

Van Büyükşehir Belediyesi (2020). Spor Faaliyetleri. 15.06 .2020 tarihinde file://C:/Users/ahmed/Downloads/stratejik plan_2020 2024.pdf adresinden erişildi.

Yücel, S.A, Atalay, A. ve Korkmaz, M. (2016). Türkiye'de yerel yönetimler ve spor hizmetleri. Nobel Bilimsel Eserler, No:13, 1.Basim, s.72

Yllmaz, A., Aydın, M., Bahadır, T. K., ve Soyer, F. (2019). A study of participation motives in sports, loneliness and depression levels of children with specific learning disabilities in terms of some variables. Journal of Human Sciences, 16(4), 978987.

Yılmaz, A., Aydın, M., Bahadır, T. K., Soyer, F. (2019). A study of participation motives in sports, loneliness and depression levels of children with specific learning disabilities in terms of some variables. Journal of Human Sciences, 16(4), 978-987.

Yıldız, K. (2018). Yerel yönetimler ve kalkınma planları çerçevesinde spor hizmetleri. Gaziantep Üniversitesi Spor Bilimleri Dergisi, 3(1),75-76. 
Yüzgenç, A.A., (2010). Yerel yönetimlerin sunduğu spor hizmetlerinde hizmet kalitesi: Ankara ili örneği. Yüksek Lisans Tezi. Yök Ulusal Tez Merkezi.

Zengin, E. ve Öztaş, C. (2008). Yerel yönetimler ve spor. Sosyal Siyaset Konferanslarn Dergisi, 55. 50-78.

5216 Sayll Büyükşehir Belediyesi Kanunu. (2004). Resmi gazete. https://www.mevzuat.gov.tr/MevzuatMetin/

\section{Kaynakça Bilgisi / Citation Information}

Mumcu, H.E., Aligül, B., Karakullukçu, Ö. F. ve Paktaş, Y. (2021). Büyükşehir belediyelerinin sportif ve rekreatif hizmetlerinin niteliklerinin incelenmesi. OPUS-Uluslararası Toplum Araştırmaları Dergisi, 17(36), 2841-2867. DOI: 10.26466/opus.806302 